\title{
Dye Coupling between Pyramidal Neurons in Developing Rat Prefrontal and Frontal Cortex Is Reduced by Protein Kinase A Activation and Dopamine
}

\author{
Birgit Rörig, Gaby Klausa, and Bernd Sutor \\ Department of Physiology, University of Munich, D-80336 Munich, Germany
}

During early postnatal development, lamina II/II pyramidal cells in rat neocortex are extensively coupled via gap junctions. The factors regulating gap junction permeability, as well as the mechanisms underlying the developmental uncoupling process are not understood. To investigate the influence of protein kinase A-mediated phosphorylation on dye coupling in the developing neocortex, pyramidal cells in slices of rat frontal and prefrontal cortex were injected intracellularly with the tracer neurobiotin. Control injections revealed clusters of about $\mathbf{3 0}$ dye-coupled neurons. Preincubation with forskolin or direct activation of protein kinase $\mathrm{A}$ with $\mathrm{Sp}$-cAMPS reduced the number of coupled cells by about $70 \%$. A significant reduction in dye coupling was also observed following incubation with dopamine. Application of receptor selective agonists and antagonists revealed that the uncoupling was mediated by both dopamine D1 and D2 receptors. The protein kinase $A$ inhibitor Rp-cAMPS reduced the effect of dopamine, suggesting that the neurotransmitter regulates gap junction permeability via protein kinase $A$ activation. In the presence of either forskolin, Sp-cAMPS, or dopamine, neurons displayed a significantly higher input resistance compared to control conditions. During the second postnatal week, transient application of forskolin to single neurons reversibly increased input resistance. At later developmental stages when coupling incidence had declined, this action of forskolin was no longer observed.

Our data demonstrate a dependence of gap junction permeability on protein kinase $A$ activity and on dopamine receptor activation in developing rat neocortical neurons. These mechanisms may modulate junctional permeability during the period of circuit formation.

[Key words: gap junctions, neocortex, development, protein kinase A, dopamine, prefrontal cortex]

During the early postnatal development of the mammalian neocortex, pyramidal neurons are extensively coupled via gap junctions (Connors et al., 1983; Cepeda et al., 1993; Peinado et al., 1993). It has been suggested that this transitory communication

\footnotetext{
Received May 3, 1995; revised July 6, 1995; accepted July 10, 1995.

We thank K. J. Feasey-Truger for reading the manuscript and G. ten Bruggencate for helpful discussions. The work was supported by the Deutsche Forschungsgemeinschaft (SFB 220/A9).

Correspondence should be addressed to Birgit Rörig. Department of Physiologry. University of Munich. Peltenkoferstrasse 12. D-80336 Munich, Germany.

Copyright 1995 Society for Neuroscience $0270-6474 / 95 / 157386-15 \$ 05.00 / 0$
}

system plays an important role during the period of circuit formation in the cerebral cortex (Yuste et al., 1992; 1995; Peinado et al., 1993). Gap junctions in the developing neocortex probably mediate the intercellular transfer of both metabolites (Kandler et al., 1994) and electrical signals (Lo Turco and Kriegstein, 1991; Yuste et al., 1995). Furthermore, they significantly influence electrotonic cell properties (Rörig et al., 1995). All these parameters might affect the efficacy and stability of developing chemical synapses. Thus, one important question is how junctional conductance is regulated by neuromodulators and other trophic factors. Gap junction permeability has been shown to be modulated by a number of physiological factors including transmembrane voltage, intracellular $\mathrm{pH}, \mathrm{Ca}^{2+}$, and phosphorylation of connexin subunits. However, apart from the sensitivity to intracellular acidification (Connors et al., 1984; Rörig et al., 1995), none of these regulatory mechanisms has been investigated so far in immature neocortical neurons.

Phosphorylation via cyclic adenosine monophosphate (cAMP)-dependent protein kinase (PKA) has been shown to affect junctional conductance in a number of neuronal and nonneuronal preparations. In rat hepatocytes (Saez et al., 1986) and canine heart cells (DeMello 1983, 1989; Burt and Spray, 1988), cAMP increases gap junction permeability. In telcost, turtle, and mammalian retinal neurons, PKA-mediated phosphorylation decreases junctional communication (Teranishi et al., 1983: Piccolino et al., 1984; Lasater and Dowling, 1985; Lasater, 1987; Hampson et al., 1992; McMahon, 1994). Activation of a number of G-protein-coupled neurotransmitter receptors increase cAMP production, resulting in an enhancement of PKA activity. Dopamine reduces gap junction coupling via DI receptor stimulation in retinal horizontal and amacrine cells of different species (Lasater and Piccolino et al., 1984; Dowling, 1985; DeVries and Schwartz, 1992; Hampson et al., 1992; McMahon, 1994; McMahon and Brown, 1994), as well as in the rat neostriatum (Cepeda et al., 1989) and nucleus accumbens (O’Donnell and Grace, 1993). The most likely mechanism of transmitter action is connexin phosphorylation, resulting in a short-term modulation of gap junctional conductance (Moreno et al., 1992).

Already at prenatal stages, the rat neocortex is invaded by a number of neuromodulatory afferents (Schmidt et al., 1982; Verney et al., 1982; Berger et al., 1985, 1991; Kalsbeek et al., 1988). In rodents, two classes of dopaminergic afferents to the prefrontal cortex have been described (Berger et al., 1985). The first arises from the A10 dopaminergic cell group of the ventral mesencephalon, reaches the prefrontal cortex by embryonic day 16 (Verney et al., 1982) and innervates all cortical layers. Dopaminergic fibers of the second class originate in the A9 group 
and reach their targets during the first and second postnatal weeks. These afferents predominantly innervate the superficial cortical layers (Berger et al., 1985). Autoradiographic binding studies have revealed an enhanced expression of dopamine DI receptors during the second and third postnatal weeks in rat prefrontal cortex (Leslie et al., 1991). A recent in situ hybridization and receptor binding study (Schambra et al., 1994) demonstrated the presence of the PKA-coupled dopamine Dl receptor (D1A) in rat ventricular cells as early as gestational day 14 .

The present study was intended to determine whether dye coupling between developing neocortical pyramidal cells is regulated by PKA activation. Following application of either forskolin, membrane-permeable cAMP analogs, or dopamine, we observed a reduction in tracer coupling between superficial pyramidal neurons. The dopamine effect was at least partially mediated via the PKA pathway, suggesting that dopaminergic afferents might be involved in the regulation of electrical and metabolic coupling of neurons during the period of formation of synaptic circuits in the neocortex.

\section{Materials and Methods}

Preparation of brain slices. Wistar rats of either sex aged between postnatal days 7 and 15 were deeply anesthetized with diethylether and decapitated. The brain was removed and chilled for $1 \mathrm{~min}$ in physiological saline at $4^{\circ} \mathrm{C}$. Coronal slices of $500 \mu \mathrm{m}$ thickness were prepared from the prefrontal and frontal regions of the cerebral cortex using a vibratome (Campden Instruments. UK). Slices were stored in artificial cerebrospinal fluid (ACSF) at room temperature for at least $1 \mathrm{hr}$. Individual slices were then transferred to a submerged type recording chamber and placed between two nylon meshes to aid mechanical stability. The slices were continuously perfused with ACSF at a flow rate of 4 $\mathrm{ml} / \mathrm{min}$; the chamber volume was $1.5 \mathrm{ml}$. The ACSF was composed of (in $\mathrm{mM}$ ): $125 \mathrm{NaCl}, 3 \mathrm{KCl}, 2.5 \mathrm{CaCl}_{2}, 1.5 \mathrm{MgCl}_{2}, 1.25 \mathrm{Nall}_{2} \mathrm{PO}_{4}, 25$ $\mathrm{NaHCO}_{3}$, and $10 \mathrm{D}$-glucose. The solution was continuously gassed with carbogen $\left(95 \% \mathrm{O}_{2} / 5 \% \mathrm{CO}_{2}\right)$, resulting in a $\mathrm{pH}$ of 7.4 at a recording temperature of $31-32^{\circ} \mathrm{C}$

Neurobiotin injections and electrophysiological recordings. To visualize dye coupling between developing neocortical neurons, neurobiotin (Vector, Burlingame, CA) was injected into single neurons. The tracer was ejected iontophoretically from microelectrodes for $10-15 \mathrm{~min}$ using subthreshold depolarizing current pulses ( $100 \mathrm{pA}, 300 \mathrm{msec}$ ). The microelectrodes were filled with $10 \%$ neurobiotin in $1 \mathrm{M} \mathrm{KCl}$. Electrode impedances ranged between 90 and $150 \mathrm{M} \Omega$. The majority of injections was performed in neurons of layers II and III. To investigate the layer specificity of the effect of dopamine, additional injections were made in cells of layers $\mathrm{V}$ and VI.

In order to analyze the effects of adenylyl cyclase stimulation or direct PKA activation on dye coupling, slices were preincubated for a period of 15-20 min with $20 \mu \mathrm{m}$ forskolin (Sigma, Deisenhofen, Germany) or $100 \mu \mathrm{M}$ of the membrane-permeable and phosphodiesteraseresistant cAMP analog Sp-adenosine-3',5'-cyclic monophosphothionate (Sp-cAMPS, Biotrend, Cologne, Germany; Van Hassert et al,, 1984; Wang et al., 1991), respectively. To investigate transmitter effects on tracer coupling, slices were incubated with $100 \mu \mathrm{m}$ dopamine (Sigma, Deisenhofen. Germany). To prevent oxidation and uptake by endogenous transporters, respectively, dopamine was applied in the presence of both the antioxidant sodium metabisulfite $\left(\mathrm{Na}_{2} \mathrm{~S}_{2} \mathrm{O}_{5}, 100 \mu \mathrm{M}\right)$ and the uptake inhibitor nomifensine maleate $(1 \mu \mathrm{M}$, Biotrend, Cologne, Germany). Solutions containing dopamine or receptor selective agonists were renewed every hour. To inhibit PKA activity, the membrane-permeable and phosphodiesterase-resistant cAMP analog Rp-adenosine3',5'-cyclic monophosphothionate (Rp-cAMPS, Biotrend, Cologne, Germany; Wang et al.. 1991) was applied at least 15-20 min before other drugs were added to the bathing solution.

The DI receptor-selective agonist SKF $38393(100 \mu \mathrm{M}$, Biotrend, Cologne, Germany) and the D2/3 receptor-specific agonist quinpirole (10 $\mu \mathrm{M}$, Biotrend, Cologne, Germany) were used to determine the receptor subtypes involved in the action of dopamine. To antagonize dopamine effects, slices were preincubated with either $5 \mu \mathrm{M}$ of the competitive D1 receptor antagonist SCH 23390 (Biotrend, Cologne, Germany), $10 \mu \mathrm{M}$ of the $\mathrm{D} 2$ receptor antagonist sulpiride (Biotrend, Co- logne. Germany), or $30 \mu \mathrm{M}$ of the combined DI and D2/3 receptor antagonist haloperidol (Biotrend, Cologne, Germany). The $\beta$-adrenergic antagonist propranolol (Biotrend, Cologne, Germany) was used to exclude dopamine effects on $\beta$-adrenoceptors. Slices were incubated in antagonist-containing solutions for at least $15 \mathrm{~min}$ before dopamine was added. Neurons were impaled after an additional 15-20 min incubation period. Following neurobiotin injection, the slices were stored for $1 \mathrm{hr}$ in gassed ACSF containing the test substances. Only one neuron was injected in each slice and the duration of tracer injection, as well as survival times after injection were standardized (minimum $10 \mathrm{~min}$ injection, $1 \mathrm{hr}$ survival time) to allow for comparison between different slices and preparations. Intracellular recordings were made using a single-electrode current- and voltage-clamp amplifier (NPI SEC-10L, Tamm, Germany). To calculate neuronal input resistance, hyperpolarizing current pulses of $100 \mathrm{pA}$ amplitude and $300 \mathrm{msec}$ duration were injected. Stimulus protocols for intracellular current injection were generated and neuronal responses were digitized using a Digidata 1200 A/D-converter (Axon instruments, CA) in conjunction with P(LAMP software (Axon Instruments. CA). Signals were filtered at $3 \mathrm{kHz}$ and stored on a computer for offline analysis. To investigate drug effects on neuronal properties, the whole-cell blind-patch technique (Blanton et al., 1989; Burgard and Hablitz, 1993) was used. Patch pipettes were pulled from borosilicate glass tubings (Clark Electromedical Instruments, UK) and were filled with a solution containing (in $\mathrm{mm}$ ): 125 $\mathrm{K}$-isethionate, $10 \mathrm{KCl}, 0.5$ ethylene glycole-bis ( $\beta$-aminoethyl ether)$\mathrm{N}, \mathrm{N}, \mathrm{N}^{\prime}, \mathrm{N}^{\prime}$-tetraacetic acid (EGTA), $10 \mathrm{~N}$-2-hydroxyethylpiperazine- $\mathrm{N}^{\prime}$ 2-ethanesulfonic acid (HEPES), and $2 \mathrm{MgATP}$. The $\mathrm{pH}$ was adjusted to 7.2. Tip resistances of the electrodes ranged between 4 and $6 \mathrm{M} \Omega$

Statistical tests were performed using the program INSTAT (GraphPad, San Diego, CA). The significance of differences in electrophysiological properties before and after drug application was determined using the two-tailed Student's $t$ test. The statistical significance of drug-induced changes in dye coupling was tested using the nonparametric MannWhitney $U$ test. Effects of receptor antagonists were analyzed by means of an ordinary ANOVA. Data are given as mean and standard error of mean (SEM). Mean values were considered to be significantly different at $p<0.05$.

Histological processing. Following injection and incubation. the slices were fixed for $1 \mathrm{hr}$ in $5 \%$ paraformaldehyde in $0.1 \mathrm{M}$ phosphatebuffered saline (PBS) and stored over night in 50\% sucrose in PBS. To visualize tracer-filled neurons, slices were resectioned at $70 \mu \mathrm{m}$ on a freeze-cut microtome (2055 Autocut, Leica Instruments). Sections were rinsed $(3 \times 10 \mathrm{~min})$ in PBS containing $\mathrm{NaCl}(0.1 \mathrm{M}, \mathrm{pH} 7.3)$ and treated $(2 \times 10 \mathrm{~min})$ with Triton $\mathrm{X}-100(0.5 \%$ in PBS $)$. The sections were then incubated for $90 \mathrm{~min}$ in avidin-conjugated horseradish peroxidase (HRP; Vector, Burlingame, CA, 1\% in PBS). Following rinses in PBS for $10 \mathrm{~min}$ and in Tris $/ \mathrm{HCl}(0.5 \mathrm{M}, \mathrm{pH} 8)$ for $2 \times 10 \mathrm{~min}$. the sections were preincubated in $0.5 \%$ diaminobenzidine (in Tris $/ \mathrm{HCl}, \mathrm{pH} 8$ ) for 15 min. Ilydrogen peroxidase solution was added at a final concentration of $0.033 \%$. The reaction was stopped by rinsing with Tris $/ \mathrm{HCl}$ (2 $\times 10 \mathrm{~min})$ and PBS $(1 \times 10 \mathrm{~min})$. Sections were then mounted on glass slides, dehydrated in ethanol, cleared in xylene, and coverslipped in Jung Tissue Freezing Medium (Leica Instruments).

Tissue sections were photographed on a Nikon Biophot (Japan) microscope. A Leitz. NPL Fluotar $40 \times$ objective and Nikon Plan $20 x$ and $10 \times$ objectives were used for photography. Neurobiotin-stained neurons or neuronal clusters were reconstructed using a Leity. Laborlux microscope and a Leitz. NPL Fluotar $40 \times$ objective with a drawing tube attached to the microscope. Cells showing damage to either soma or principal dendrites were excluded from analysis. Analysis was restricted to cells of comparable staining intensity, i.e.. similar diffusion gradients for the tracer can be assumed.

\section{Results}

Effects of forskolin and Sp-cAMPS on die coupling between layer II/III pyramidal neurons

To test whether an increase in intracellular cAMP levels modulates dye coupling, slices were incubated in $20 \mu \mathrm{M}$ forskolin. Injections were performed in the medial precentral area of the prefrontal cortex, as well as in adjacent frontal areas, and were confined to the superficial layers. Since dye coupling gradually decreases during the developmental period under investigation (Connors et al., 1983; Peinado et al., 1993), data from 2-3 con- 



Figure 1. Micrographs of neurobiotin-filled superficial pyramidal cells of the prefrontal cortex injected under control conditions $(A)$ and after incubation in $20 \mu \mathrm{M}$ forskolin $(B$ and $C$ ). The control neuron from a P9 animal showed extensive tracer coupling to neighboring neurons. Dye coupling between pyramidal cells was significantly reduced when injections were performed after 15-20 min incubation in forskolin. Age of animals: $B-\mathrm{P} 9, C-\mathrm{P} 8$. The top of the illustrations represents the pial surface. Scale bar: $50 \mu \mathrm{m}$. 

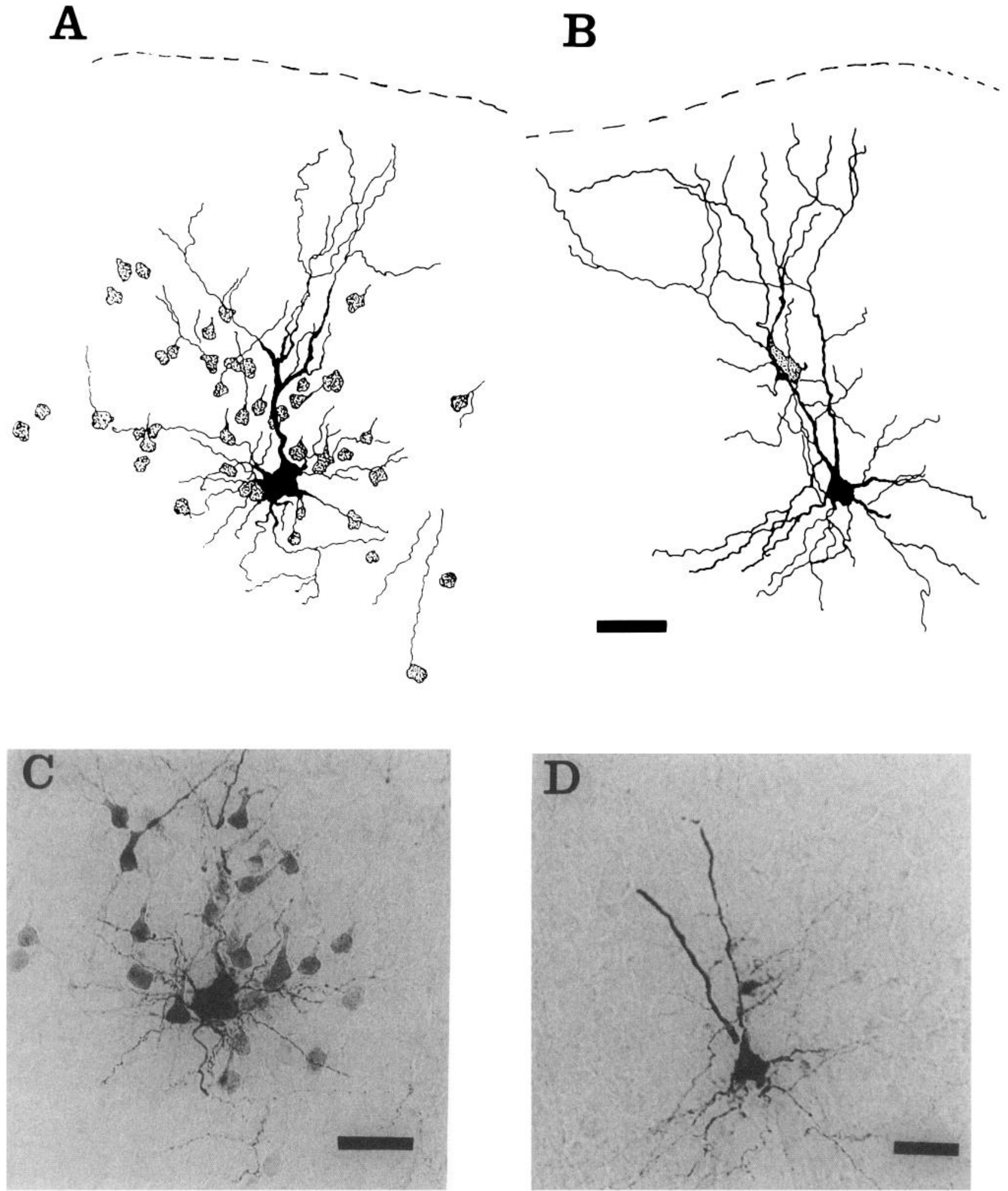

Figure 2. Camera lucida reconstructions $(A$ and $B)$ and micrographs $(C$ and $D)$ of a control neuron $(A$ and $C)$ and a pyramidal cell after incubation in Sp-cAMPS $(100 \mu \mathrm{M})$, respectively. Both cells were located in layer II/III. The reconstructions show the complete morphology and extent of tracer coupling, as well as the distance from the pial surface (dashed line). The control cell (P8) shows widespread tracer coupling $(A$ and $C$ ). Incubation with Sp-cAMPS resulted in an almost complete uncoupling of the neuron (P9) shown in $B$ and $D$. Scale bar: $50 \mu \mathrm{m}$. 




Figure 3. Effects of the adenylyl cyclase activator forskolin and the direct protein kinase A activator Sp-cAMPS on dye coupling between lamina II/III pyramidal neurons. Both substances produced a decrease in the average number of coupled cells per injection by approximately $70 \%$. Injections were performed between $\mathrm{P} 7$ and P10; the number of cells injected in each group is shown in parentheses. The difference in mean cluster size between controls and pretreated slices was statistically significant (Mann-Whitney $U$ test). In this and the following figures, the bars represent mean \pm SEM

secutive postnatal days have been pooled. Control injections made on postnatal days $8-10(\mathrm{P} 8-10)$ resulted in a mean number of $30.4 \pm 5.7(n=14)$ cells coupled to the injected neuron (range 8-67 cells). After preincubation with forskolin, a marked reduction in cluster size became evident (Fig.1). On P7-9, the mean number of neurons dye coupled to the core cell was reduced to $7.8 \pm 3.3(n=19)$ after forskolin treatment (Fig. 3). The difference between the mean values was statistically significant $(p<0.0001$, Mann-Whitney $U$ test). In the presence of forskolin, tracer injection resulted in a single stained neuron in one case, and in only 2 out of 19 slices were clusters of more than 20 coupled neurons observed. In comparison, under control conditions (at P7-10), single stained, i.e., uncoupled neurons were never detected, and 9 out of 14 injections revealed clusters of more than 20 cells.

A similar result was obtained when slices were incubated with the direct PKA activator Sp-cAMPS $(100 \mu \mathrm{M})$. The mean cluster size on $\mathrm{P} 9 / 10$ was $24.1 \pm 5.9(n=10)$ under control conditions and $7.7 \pm 6.3(n=7)$ in the presence of Sp-cAMPS (Figs. 2 and 3$)$. The mean values differ significantly $(p<0.01)$. Com- plete Sp-cAMPS-induced uncoupling was observed in three slices.

\section{Effect of dopamine on dye coupling}

To investigate whether dopaminergic mechanisms might be involved in the control of gap junction coupling during cortical development, intracellular injections of neurobiotin were made in the presence of dopamine. The injections were performed in slices obtained from 7-15-d-old animals and were made predominantly in an area of the cerebral cortex receiving strong dopaminergic input, i.e., the medial precentral part of the prefrontal cortex. Figure 4 shows a neuron injected in the presence of nomifensine and sodium metabisulfite (B) as well as neurobiotin-labeled cells after incubation with $100 \mu \mathrm{M}$ dopanine (A, C). Due to the strong developmental decline in cluster size, neurons were split into three age groups in order to quantify the dopamine effect (Fig. 5). On P8/9, the cluster size was significantly reduced $(p<0.04)$ from a mean of $37.4 \pm 8.0(n=7)$ under control conditions to a mean of $14.0 \pm 4.4(n=7)$ in the presence of dopamine. A statistically significant reduction from a mean of $17.6 \pm 3.9(n=13)$ coupled neurons to a mean of $5.0 \pm 1.3(n=8)$ was also observed on P10/11. Even between P12 and P15, when a strong developmental reduction in cluster size had already occured, dopamine still produced a statistically significant decline in dye coupling from a mean of $6.4 \pm 2.1(n$ $=24$ ) coupled cells under control conditions, to $2.0 \pm 0.4(n$ $=18$ ) in the presence of dopamine. Thus, a dopaminergic modulation of gap junction coupling between layer II/III pyramidal cells is likely to exist during the entire postnatal period.

To investigate reversibility of the uncoupling action of dopamine a sample of P10 neurons was preincubated and injected in the presence of dopamine. Then slices were superfused for a perid of $1.5 \mathrm{hr}$ with dopamine-free solution containing only the antioxidant and uptake inhibitor. Under these conditions we have observed only reduced recovery: four out of five neurons were coupled to one to seven neighboring cells, whereas a large cluster conlaining 26 coupled neurons was observed in only one case. This suggests that the long presence of the transmitter (up to $\mathrm{l} \mathrm{hr}$ ) might activate secondary processes leading to prolonged or even permanent uncoupling.

To exclude effects of the added antioxidant and the uptake inhibitor on dye coupling, control injections after incubation in $\mathrm{Na}_{2} \mathrm{~S}_{2} \mathrm{O}_{5}(100 \mu \mathrm{M})$ and nomifensine $(1 \mu \mathrm{M})$ without addition of dopamine were performed in slices from rats aged between P7 and P10. These substances had no significant effect on cluster size (Figs. 4 and 5). The mean number of coupled cells under control conditions was $30.4 \pm 5.7(n=14)$ and $37.0 \pm 9.9(n$ $=7$ ) after incubation in antioxidant and uptake inhibitor. Thus, the reduction in cluster size observed after incubation in dopamine can be considered as a specific effect of the neurotransmitter.

Since dopamine applied at high concentrations might exert nonspecific effects via $\beta 1$-adrenoceptors (Nicoll et al., 1990), we injected a sample of neurons in the presence of dopamine

Figure 4. Micrographs of layer II/III neurons injected in the presence of dopamine ( $100 \mu \mathrm{M} ; A$ and $C)$ and after incubation in sodium metabisulfite and nomifensine without addition of the transmitter $(B)$. In the neuron shown in $A(P 10)$, dopamine induced complete uncoupling. In $C$ (P 11$)$, residual coupling to three other cells is observed. Preincubation in sodium metabisulfite $(100 \mu \mathrm{M})$ and nomifensine maleate ( $1 \mu \mathrm{M})$ had no significant effect on dye coupling. The neuron (P10) shown in $B$ displays extensive coupling similar to that observed under control conditions. Scale bar: $50 \mu \mathrm{m}$. 




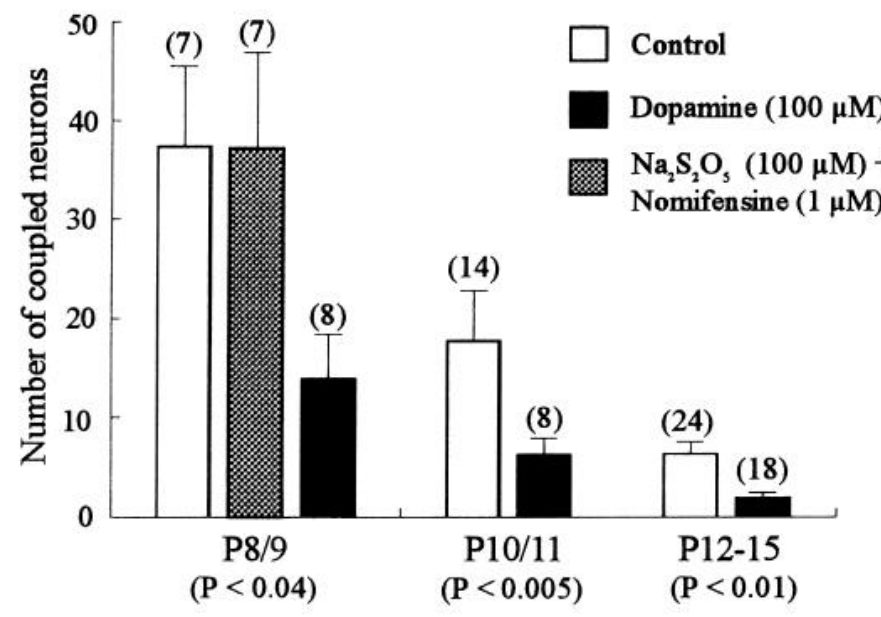

Figure 5. Effect of dopamine on the size of neurobiotin-labeled cell clusters. Since coupling declines during postnatal development, neurons were splitted into three age groups. Dopamine induced a statistically significant (Mann-Whitney $U$ test) reduction in the number of coupled cells per injection in all three age groups. Injections performed after incubation of slices in sodium metabisulfite and nomifensine in the absence of dopamine yielded dye-coupled clusters of sizes similar to those observed under control conditions. The number of cells injected in each group is shown in parentheses.
$(100 \mu \mathrm{M})$ and the $\beta$-adrenoceptor antagonist propranolol (10 $\mu \mathrm{M})$. Under these conditions, dopamine still produced a significant reduction $(p<0.005)$ in the number of cells coupled to the injected neuron from a mean of $30.4 \pm 5.7(n=14)$ to a mean of $8.9 \pm 5.5(n=8$, Fig. 7). Thus, despite the relatively high concentration used, we can exclude that the dopamine-induced decrease in gap junction coupling was mediated via $\beta$-adrenoceptors. Our results demonstrate a marked reduction in dye coupling following activation of protein kinase A and following activation of dopamine receptors, respectively. Some dopamine receptor subtypes are linked to the cAMP-PKA system. We therefore investigated whether the dopamine effect was mediated by this intracellular signal transduction pathway. Slices were incubated in dopamine and the PKA inhibitor Rp-cAMPS (100 $\mu \mathrm{M})$. Under these conditions, we observed reduced cluster sizes on P8-10 (18.1 $\pm 5.7, n=7)$. However, this mean value was not statistically different from those obtained under control conditions (31.6 $\pm 6.9, n=11, p=0.2109$, Figs. 6 and 7). Thus, direct inhibition of protein kinase $\mathrm{A}$ at least partially antagonized the uncoupling effect of dopamine, suggesting that PKA-coupled dopamine receptors were involved in this action.

In order to determine which types of dopamine receptors modulate gap junction permeability, the effects of receptor selective agonists and antagonists were investigated. $A$ rise in
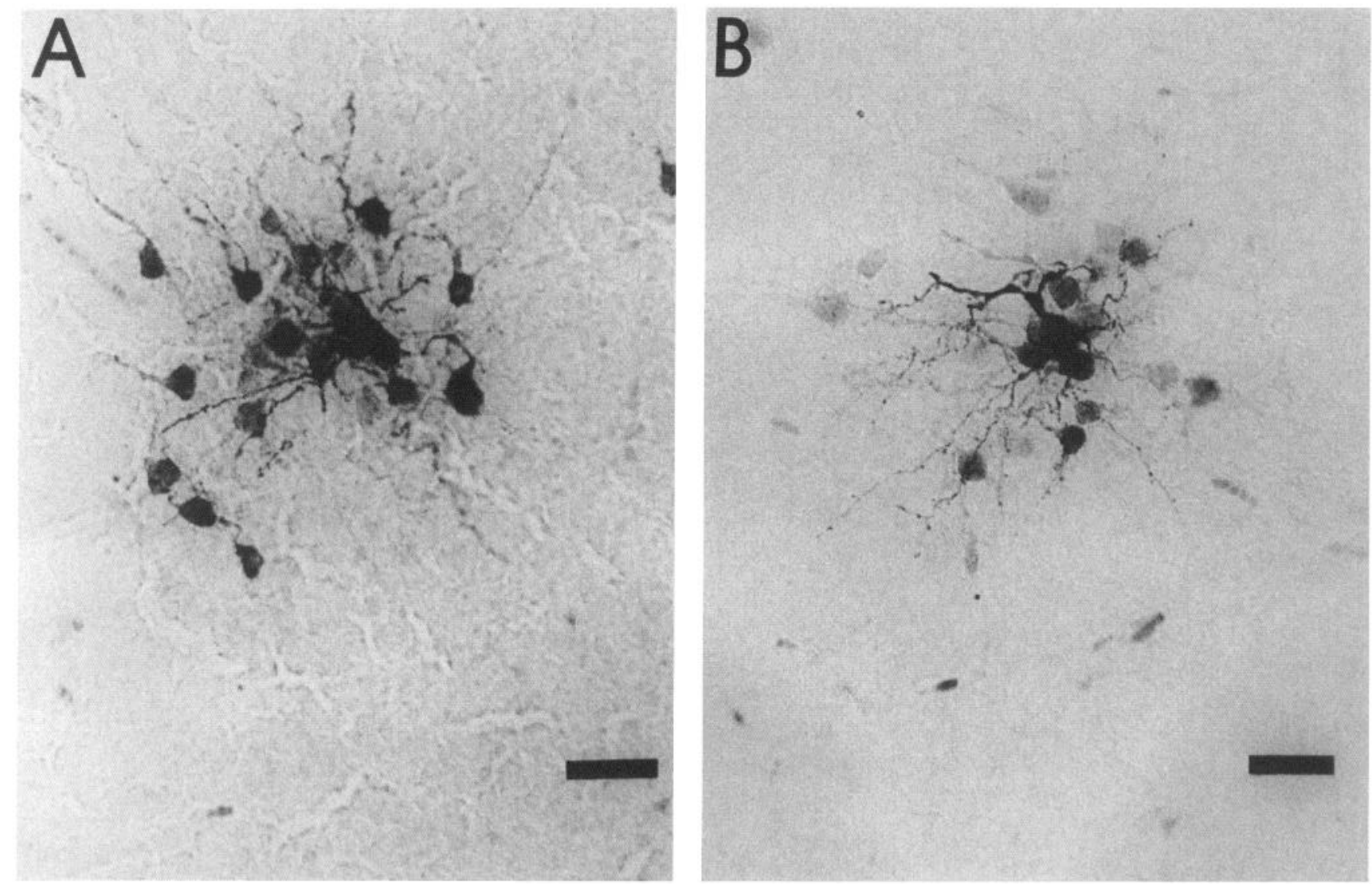

Figure 6. Effects the protein kinase A inhibitor Rp-cAMPS on dopamine-induced uncoupling of neurons. Injections performed in the presence of dopamine $(100 \mu \mathrm{M})$ and the protein kinase A inhibitor Rp-cAMPS $(100 \mu \mathrm{M})$ resulted in dye-coupled clusters $(B)$, which were often of similar size to those observed under control conditions $(A)$. Cells shown in $A$ and $B$ were injected on P8. Scale bar: $50 \mu \mathrm{m}$. 


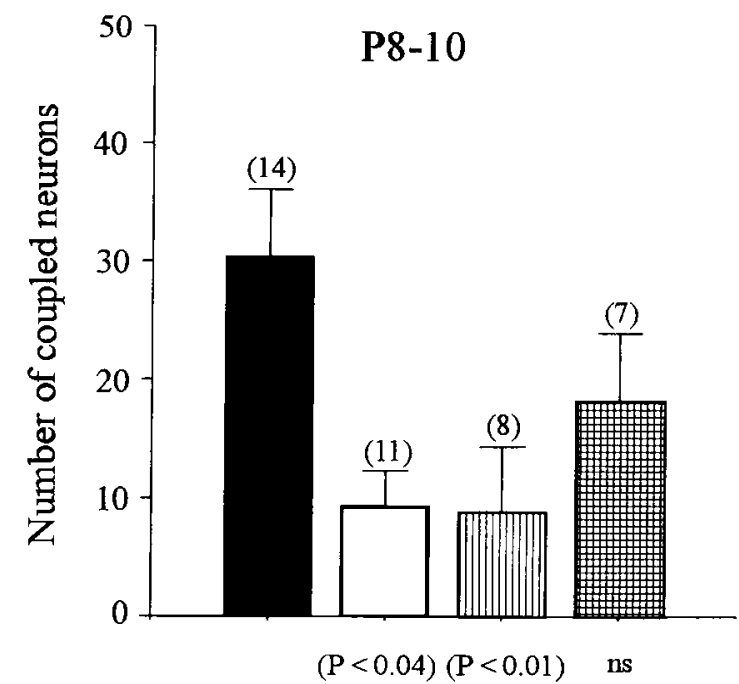

Control

\section{Dopamine $(100 \mu \mathrm{M})$}

III Dopamine $(100 \mu \mathrm{M})+$ Propranolol $(10 \mu \mathrm{M})$

$$
\text { Dopamine }(100 \mu \mathrm{M})+\mathrm{Rp}-\mathrm{AMMS}(100 \mu \mathrm{M})
$$

Figure 7. Effects of propranolol and Rp-cAMPS on dopamine-induced uncoupling of neurons. The reduction in cluster size was still observed in the presence of the $\beta$-adrencrgic antagonist propranolol, demonstrating that the dopamine effect was not mediated by $\beta$-adrenoceptors. Inhibition of protein kinase $A$ by Rp-cAMPS resulted in smaller clusters compared to control conditions, but the difference was no longer statistically significant (Mann-Whitney $U$ test). Numbers of injections performed are shown in parentheses.

intracellularcAMP has been shown to be triggered by a subtype of the D1 receptor, the D1A receptor (Dearry et al., 1990; Monsma et al., 1990; Zhou et al., 1990). We therefore tested the effect of the D1 receptor agonist SKF 38393 on tracer coupling. Preincubation in $100 \mu \mathrm{M}$ SKF 38393 resulted in a significant reduction in dye coupling both on P7-9 $(p<0.02)$ and on P11 $(p<$ 0.001 , Figs. $8 A, C$ and $9 A$ ), suggesting strongly that D1 receptors contribute to the uncoupling action of dopamine. However, the D2/D3 receptor agonist quinpirole $(10 \mu \mathrm{M})$, although less effective, also caused a statistically significant $(p<0.04)$ reduction in cluster size (Figs. $8 B$ and $9 A$ ) on P7-9.

In the presence of dopamine and the selective D1 receptor antagonist SCH $23390(5 \mu \mathrm{M})$, the cluster size was found to be slightly reduced, but not significantly different to controls (Fig. $9 B$ ). A weak antagonism of the dopamine effect was also observed upon application of the competive D2 receptor antagonist sulpiride $(10 \mu \mathrm{M}$, Fig. $9 B$ ). The analysis of variance (nonparametric Kruskal-Wallis ANOVA) revealed that the antagonistic effects of both SCH 23390 and sulpiride were statistically significant $(p<0.03)$. However, ANOVA posttests (Dunn's Multiple Comparison Test) showed that the cluster sizes observed in the presence of the antagonists were significantly different from controls, but not significantly different from the cluster size obtained in the presence of dopamine alone. After incubation in dopamine and haloperidol $(30 \mu \mathrm{M})$, a combined D1/D2 receptor antagonist, the cluster size was found to be not statistically different from control values $(p=0.19)$ and significantly larger $(p$ $<0.04$ ) than the mean cluster size found in slices incubated exclusively in dopamine (Fig. 9B). Thus, the most effective antagonism of the dopamine effect on dye coupling between superficial layer pyramidal cells in the prefrontal cortex was achieved by blocking both D1 and D2 dopamine receptors.

Since deep cortical layers receive the first dopaminergic afferents during development and the strongest dopaminergic innervation in the adult rat, additional neurobiotin injections were performed in layer $\mathrm{V}$ and VI neurons, respectively, to examine layer specificity of the dopamine effect. Control injections in layers V/VI on P8-10 resulted in a much smaller number of coupled cells per injected neuron compared to superficial superficial layers $(2.3 \pm 1.32, n=7$, Figs. 10 and 11). Injections performed in the presence of dopamine $(100 \mu \mathrm{M})$ did not significantly ( $p=0.37$ ) change the number of dye-coupled neurons (3.2 $\pm 0.8, n=6$, rig. 11$)$.

\section{Effects of dopamine, Sp-cAMPS, and forskolin on membrane potential and input resistance}

In order to analyze to what extent dopamine, PKA activating agents, or receptor-selective agonist affect neuronal properties, resting membrane potential and input resistance were measured in control and test solutions prior to intracellular injection of neurobiotin. Figure 13 summarizes data obtained from neurons ranging from P7 to P11. None of the substances tested (dopamine, forskolin, Sp-cAMPS) significantly altered the average resting membrane potential of the neurons. In contrast, the average neuronal input resistance was found to be significantly increased after preincubation in each of these substances (Fig. 13).

Since a reduction in gap junction permeability should change electrotonic cell properties, we investigated the effects of forskolin on electrotonic parameters. Application of $20 \mu \mathrm{M}$ forskolin reversibly increased neuronal input resistance by $29-165 \%$ in five out of nine neurons tested (Fig. 12A). This enhancement in membrane resistance should result in a potentiation of the amplitudes of excitatory postsynaptic potentials (EPSPs). However, since forskolin markedly augments $\mathrm{GABA}_{\mathrm{A}}$-mediated inhibitory postsynaptic potentials (IPSPs, Penit-Soria et al., 1987; Sutor and Mayr, 1991) and since $\mathrm{GABA}_{\mathrm{A}}$ receptor blockade induces epileptiform activity in the neocortex (Gutnick et al., 1982; Lee and Hablitz, 1991), the effect of forskolin on EPSPs could not be studied directly. We therefore injected transient currents resembling glutamatergic synaptic currents $(100 \mathrm{pA}$ amplitude, $1 \mathrm{msec}$ time to peak, $5 \mathrm{msec}$ decay time) and recorded the corresponding voltage responses. These voltage deflections were reversibly potentiated by $33-575 \%$ in seven out nine cells (Fig. 12B). Effects of forskolin on current-induced electrotonic potentials were not observed in neurons on P17/18 $(n=6$, Fig. $12 C, D$ ), i.e., at a time when the extent of dye coupling had declined to a minimum. This finding strongly suggests that the forskolin-induced alterations in electrotonic potentials detected in younger neurons were due to a reduction in gap junctional conductance rather than to an action of forskolin on calciumdependent potassium currents (Hiramatsu et al., 1994), or voltage-gated sodium conductances (Ono et al., 1995).

\section{Discussion}

The present study provides evidence for a regulation of gap junction coupling between superficial pyramidal neurons in rat prefrontal and frontal cortex by protein kinase A. A significant reduction in neuronal dye coupling, as well as a prominent effect on input resistance was observed after adenylyl cyclase activa- 

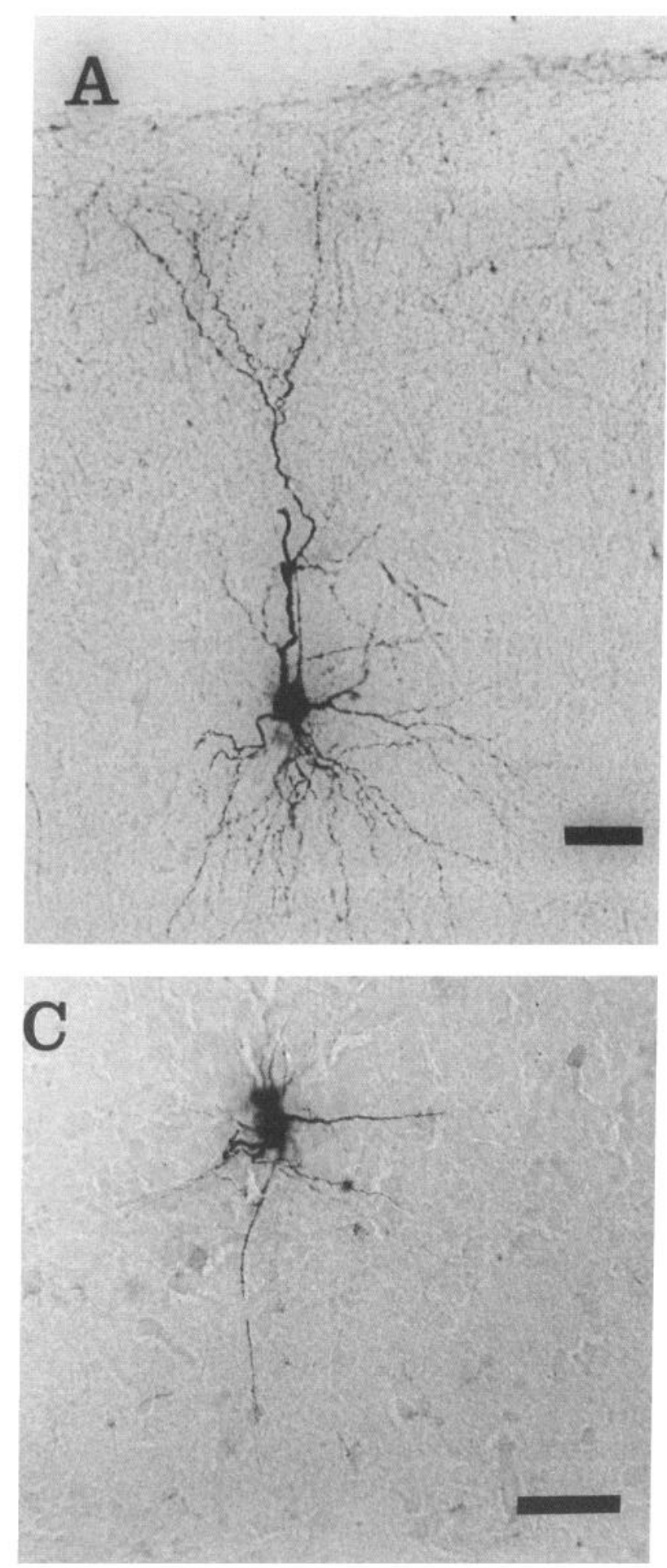

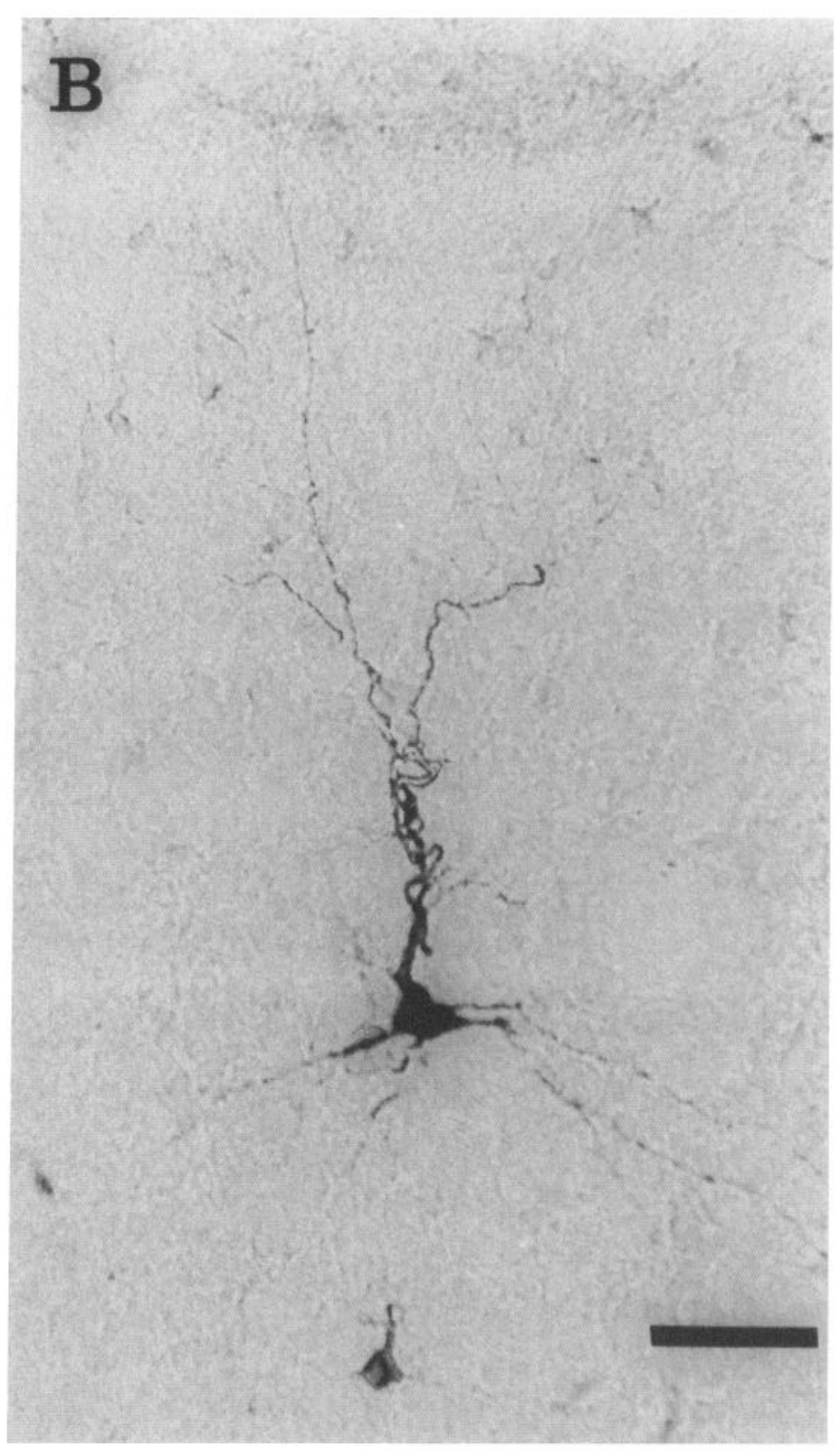

Figure 8. Micrographs of layer II/III cells injected in the presence of the D1 receptor selective agonist SKF 38393 (100 $\mu \mathrm{M} ; A$ and $C$ ) and the D2/3 receptor selective agonist quinpirole $(10 \mu \mathrm{M} ; B)$, respectively. SKF 38393 induced significant uncoupling on both P11 $(A)$ and $\mathrm{P} 7(C)$. Quinpirole also significantly reduced dye coupling. The neuron shown in $B$ was injected on P7. Scale bar: $50 \mu \mathrm{m}$.

tion by forskolin and direct PKA activation by Sp-cAMPS. Dopamine also induced a marked reduction in gap junction coupling. The transmitter effect was partially mediated by D1 receptor-stimulated PKA activation. Thus, we propose that dopaminergic afferents to the neocortex might be involved in the regulation of electrotonic and metabolic coupling between pyramidal neurons during early postnatal development.
We have used dye coupling as our major assay system to elucidate the mechanisms regulating gap junctional communication. The tracer neurobiotin has been repeatedly used as an indicator of dye coupling between cortical neurons (Peinado et al., 1993). To allow for comparison between individual slices from different animals, we standardized injection and survival times of slices after injection. Only one neuron was injected in 

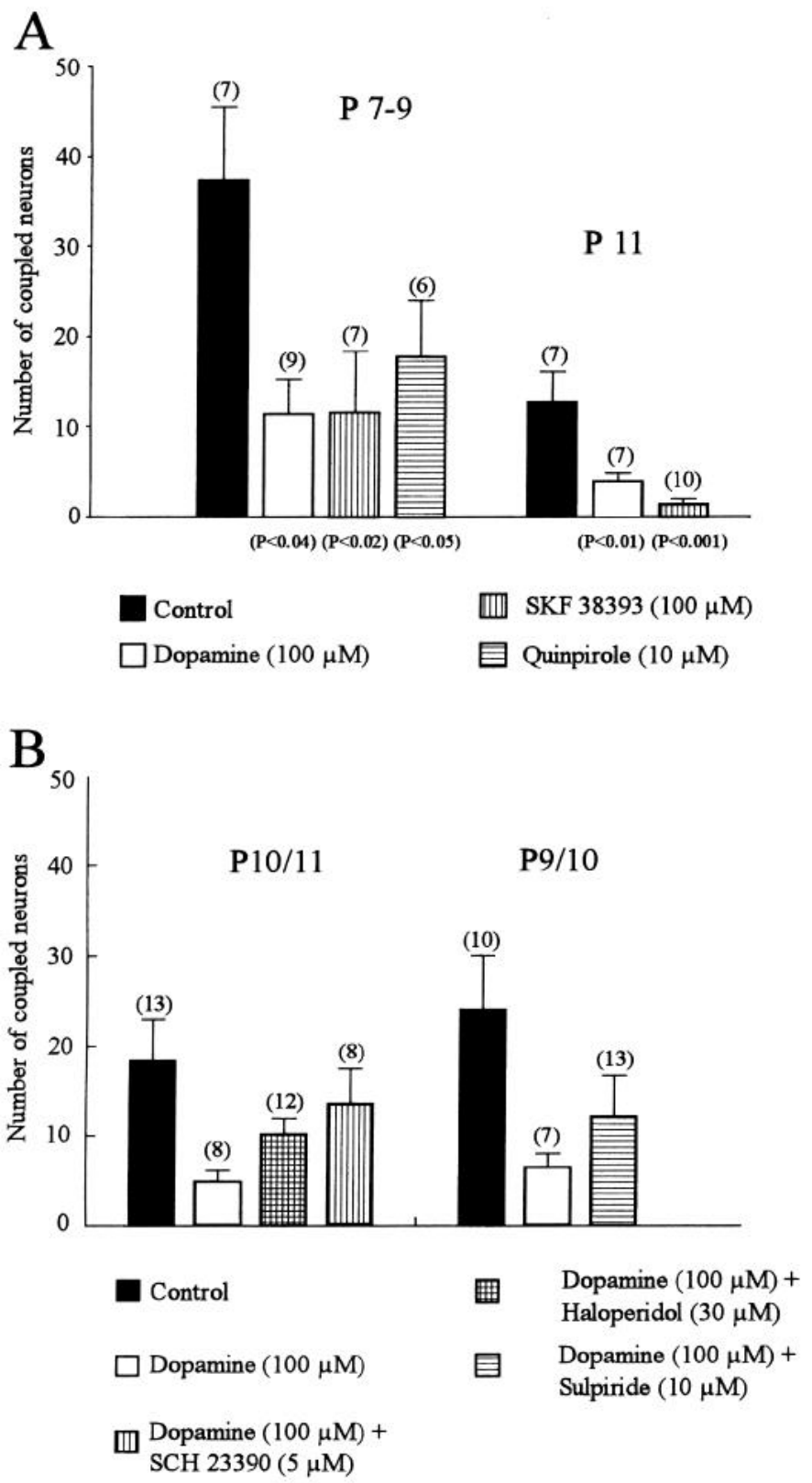

Figure 9. Effects of dopamine receptor selective agonists and antagonists on dye coupling. A, Effects of receptor selective agonists. The D1 receptor agonist SKF 38393 reduced dye coupling as efficiently as dopamine both between P7 and P9 and on P11. The D2/3 receptor agonist quinpirole was less effective, but the reduction in the number of coupled neurons per injection was also statistically significant (Mann-Whitney $U$ test). B, Effects of receptor selective antagonists. After incubation in dopamine and either the D1 receptor antagonist SCH 23390 or the D2 receptor antagonist sulpiride, the size of neurobiotinlabeled cell clusters was no longer statistically significant from controls (ANOVA, $P<0.03$ ). The most effective antagonism of the uncoupling action of dopamine was achieved by incubation in dopamine and the D1/D2 receptor antagonist haloperidol (for $P$ values, see text).

Figure 10. Camera lucida reconstruction and micrograph of a layer $\mathrm{V}$ neuron injected under control conditions. The camera lucida reconstruction in $B$ demonstrates the distance from the pial surface (dashed line). Already under control conditions dye coupling between deep layer neurons was very weak. Injections were performed on P10, when lamina II/III cells still show extensive coupling. Scale bar: $50 \mu \mathrm{m}$.
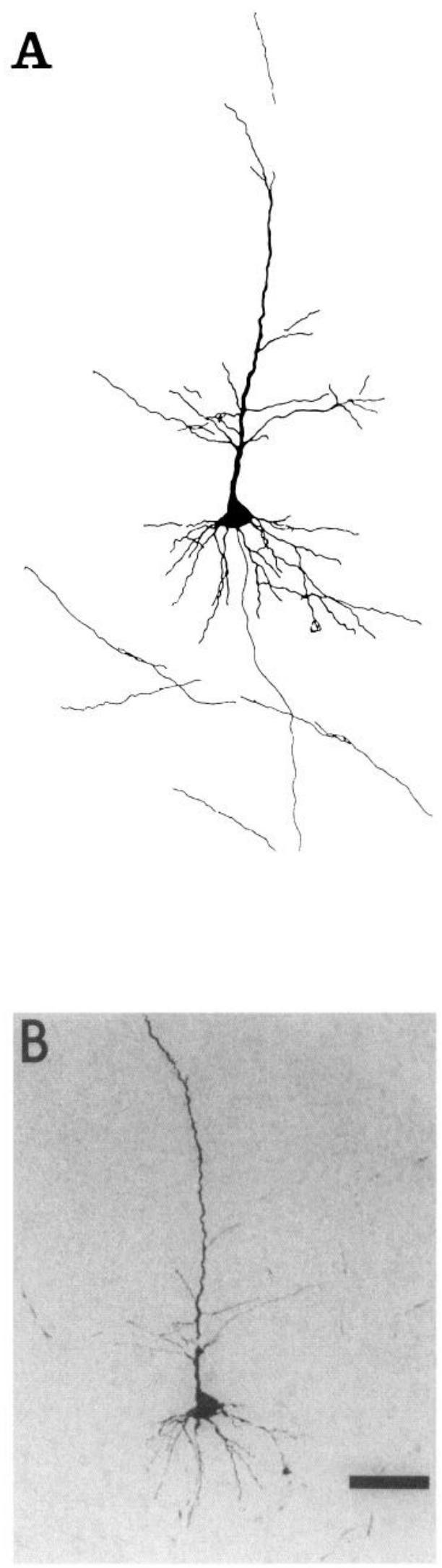


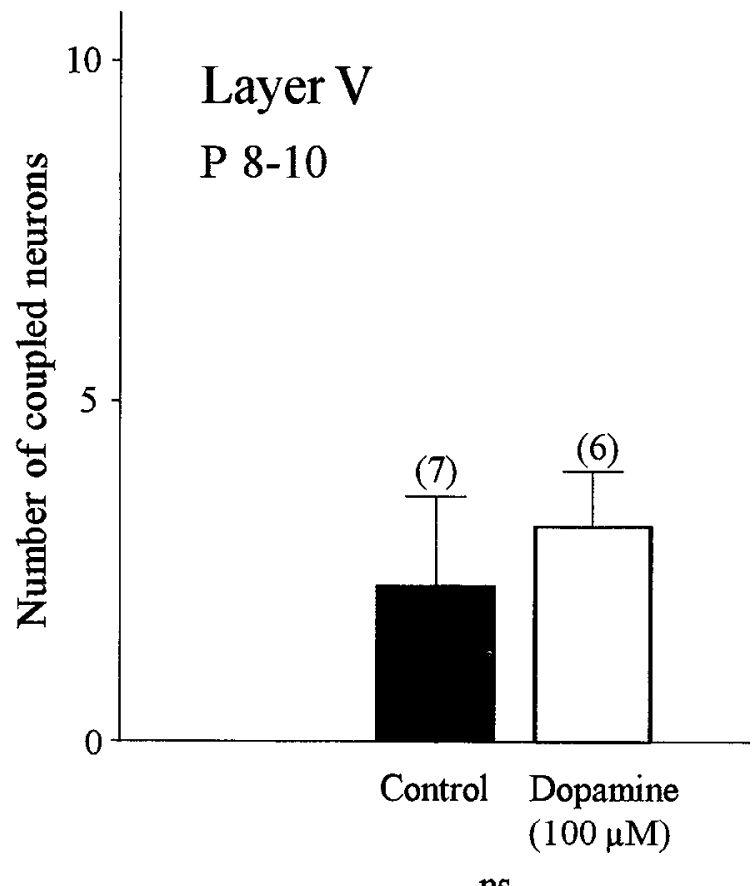

ns

Figure 11. Dye coupling between deep layer pyramidal neurons. The number of coupled neurons per injection was significantly lower in comparison to superficial neurons. Dopamine had no statistically significant effect on tracer coupling in layer V/VI neurons (Mann-Whitney $U$ test).

each slice and only pyramidal-shaped neurons were included into the analysis. The extent of coupling was assessed by counting the coupled somata in the vicinity of the injected neuron.

To investigate transmitter effects on dye coupling, slices were incubated for 1.5 to $2 \mathrm{hr}$, including preincubation and survival times, in ACSF containing a rather high agonist concentration. Therefore, desensitization of receptors resulting in an underestimation of the effect cannot be excluded. However, the reduction in dye coupling was of high statistical significance. We used high agonist concentrations mainly for two reasons: (1) dye coupling displays high variability already under control conditions, and (2) receptor densities might he low as compared to the adult cortex. Furthermore, among the various dopamine receptor subtypes, the affinity for dopamine is lowest at the D1 and D2 receptors (Schwartz et al., 1992). The dopamine-induced uncoupling could be mimicked by both the D1 receptor selective agonist SKF 38393 and the D2 receptor selective agonist quinpirole. It was also observed in the presence of the $\beta$-adrenoceptor antagonist propranolol. These findings provide strong evidence for a dopamine effect selectively mediated by dopamine receptors. Since we used high agonist concentrations, the observed uncoupling effect of dopamine could not be completely suppressed by receptor selective antagonists applied in the "normal" pharmacological concentration range. Nevertheless, in neurons pretreated with dopaminergic antagonists, the reduction in clustcr sizc induced by subscquent treatment with dopaminc failed to reach statistical significance. In retinal amacrine cells, the antagonizing effect of SCH 23390 has been shown to depend strongly on the dopamine/SCH 23390 concentration ratio (Hampson et al., 1992). However, we did not further increase antagonist concentrations, since this might have resulted in a loss of receptor subtype selectivity.
In order to quantify effects on dye coupling, dopamine was bath applied, and coupling within the entire dendritic tree of the injected cell was analyzed. However, local uncoupling due to transmitter release at single modulatory terminals affecting only single dendrites or even parts of dendrites is likely to occur under physiological conditions. Although dopamine is released predominantly from varicosities and might reach its receptors by diffusion over relatively large distances, dopaminergic terminals have also been shown to be involved in triadic synaptic complexes in both rodent (Verney et al., 1990) as well as primate (Goldman-Rakic et al., 1989) prefrontal cortex, suggesting highly localized effects of the transmitter. The distance between dopaminergic release sites and gap junctions, however, is not known to date, and whether dopamine receptors are located in close proximity to junctional complexes also remains to be shown. Since dopamine receptor-mediated uncoupling of gap junctions might occur via widespread "volume neurotransmission" (i.e., undirected spread of transmitter in a larger volume of cortical tissue; Lidow, 1995) or in a highly localized fashion, it is unclear whether activation of dopaminergic afferents uncouples an assembly of neurons, e.g., an entire column, single neurons, or only local dendritic compartments from the functional syncytium.

We have only analyzed the effects of exogeneous transmitter on dye coupling without attempting to stimulate release from dopaminergic terminals in the slice preparation. Dopaminergic fibers originating in the brainstem are cut during preparation and the diffusely projecting dopaminergic afferents are difficult to stimulate. The dopamine uptake inhibitor nomifensine did not reduce dye coupling, indicating that spontaneously released dopamine does not reach concentrations high enough to significantly affect gap junction coupling. Microelectrodes rather than patch pipettes were used for tracer loading of pyramidal cells to exclude false negative results due to washout of components of intracellular second messenger pathways. However, to obtain higher resolution recordings, we used the patch-clamp technique to study the influence of gap junction closures on electrotonic potentials. Under these conditions, forskolin, which most effectively reduced tracer coupling, exerted effects on electrotonic potentials in five out of nine neurons tested. The lack of effect in four cells might be due partially to a long electrotonic distance between the location of gap junctions and the recording site, although a dialysis of intracellular components might also have taken place by the time PKA-mediated phosphorylation reduces junctional communication.

Cyclic adenosine monophosphate and dopamine as negative regulators of gap junctional communication during postnatal development of the neocortex

In different tissues, PKA stimulation has heterogeneous effects on gap junction coupling. Whereas coupling is enhanced in some non-neuronal tissues (DeMello 1983; Saez et al., 1986; Burt and Spray, 1988; DeMello 1989), an inhibitory effect of PKA activation has been shown in the vertebrate retina (Teranishi et al., 1983; Piccolino et al. 1984; Lasater and Dowling, 1985; Lasater, 1987; DeVrics and Schwartz, 1992; Hampson et al., 1992; McMahon, 1994). Our results demonstrate a suppressive effect of raising intracellular cAMP concentrations on dye coupling in the developing rat neocortex. This second-messenger pathway is regulated by a number of G-protein-coupled neurotransmitter receptors, suggesting that chemical and electrical communication systems are closely interrelated in the immature neocortex. 
P9

A

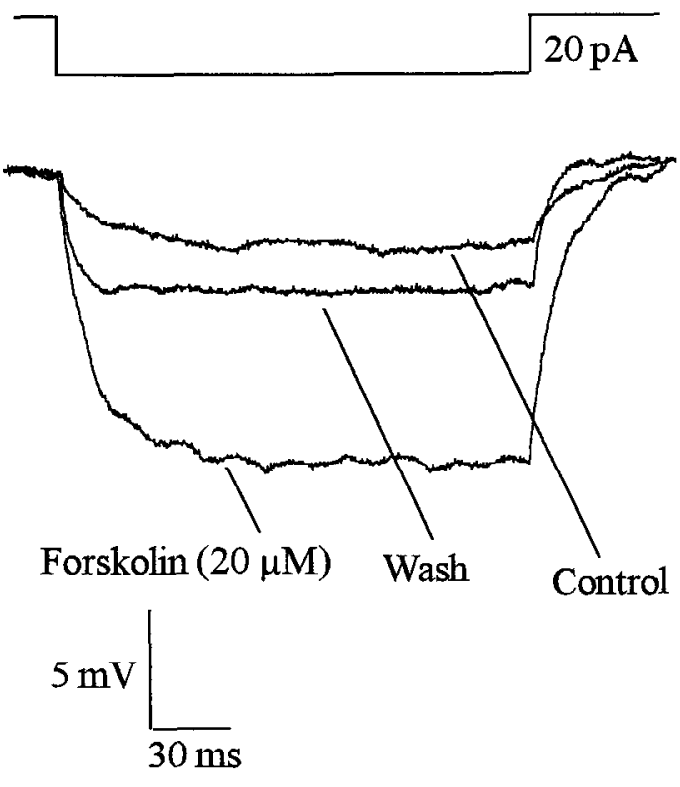

P17

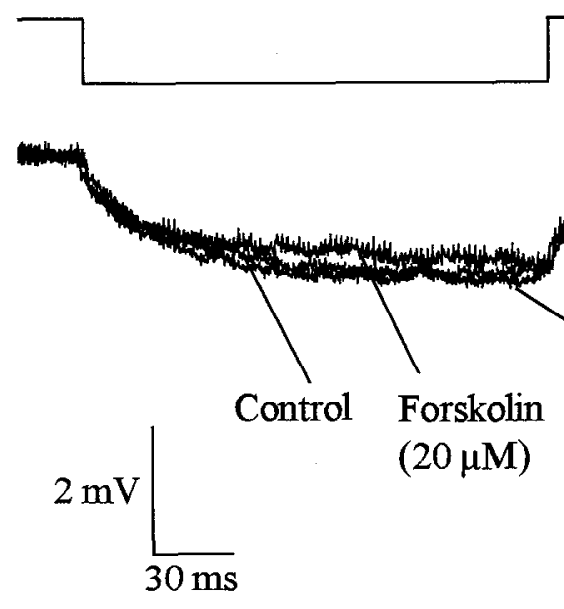

D
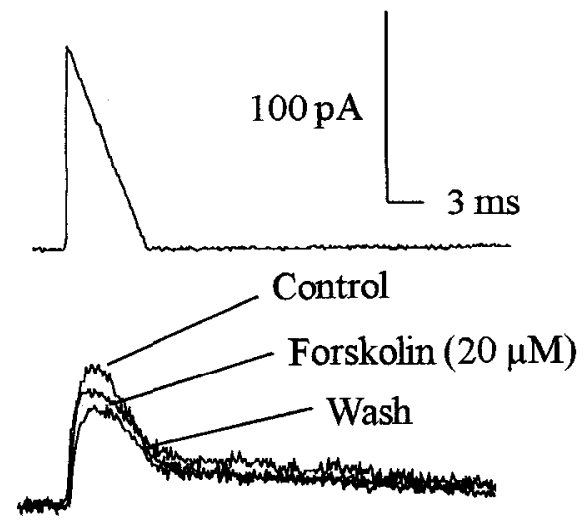

\section{$20 \mathrm{pA}$}

$1.5 \mathrm{mV}$

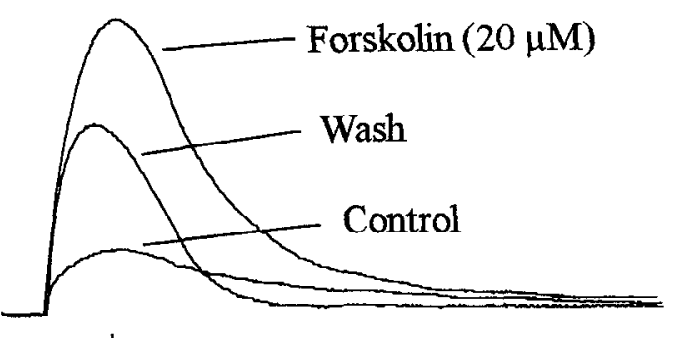

$\frac{L_{10 \mathrm{~ms}}}{1.5 \mathrm{mV}}$

$100 \mathrm{pA}$

$10 \mathrm{~ms}$
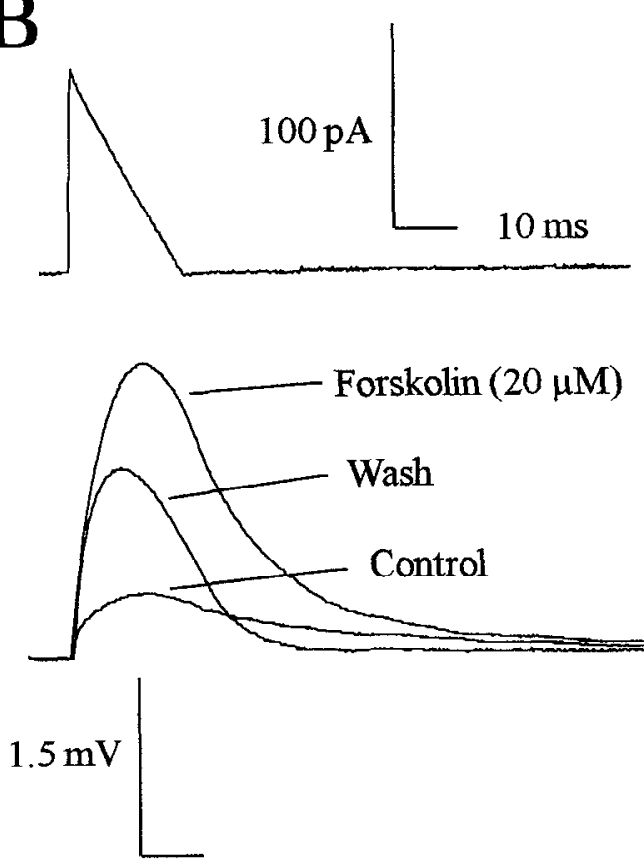

\section{Forskolin $(20 \mu \mathrm{M})$}




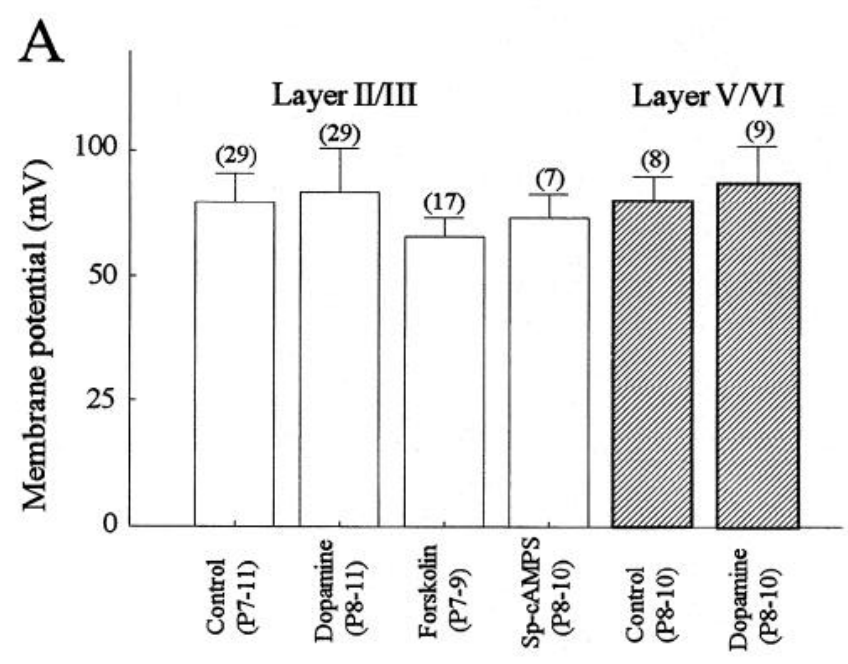

B

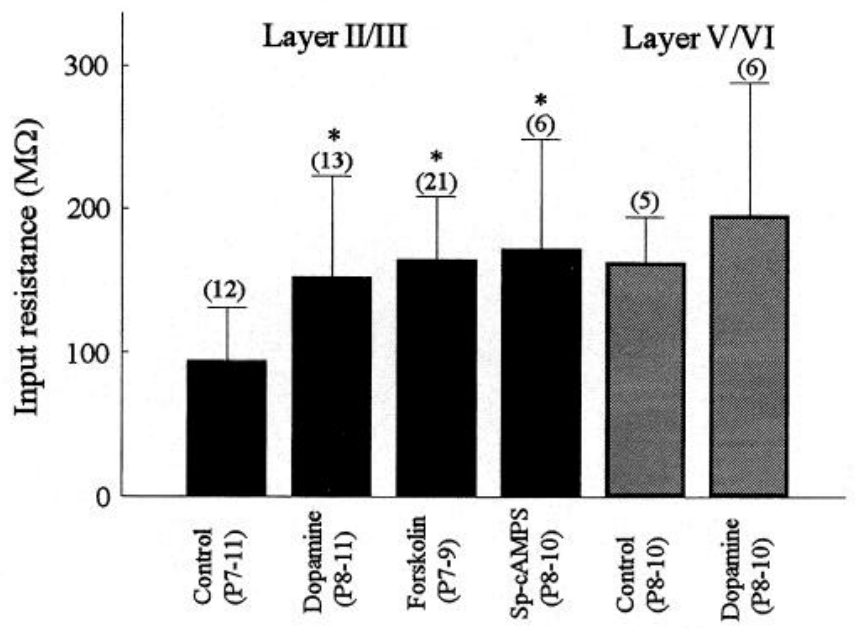

Figure 13. Comparison of mean membrane potentials $(A, \pm \mathrm{SD})$ and input resistances $(B)$ of neurons (P7-11) under control conditions and after preincubation with forskolin, Sp-cAMPS and dopamine. Whereas resting membrane potentials were not significantly altered, all three substances produced a statistically significant increase in input resistance (two-tailed Student's $t$ test) in lamina II/III neurons as compared to agematched control neurons. In neurons of deep cortical layers, dopamine did not significantly increase input resistance. Statistical significance is indicated by asterisks.

We have not directly demonstrated a PKA-mediated phosphorylation of connexins, i.e., the observed reduction in dye coupling might be indirectly induced via phosphorylation of a different protein. Stimulation of the PKA pathway via D1 receptors has recently been shown to modulate voltage-activated calcium currents in striatal neurons (Surmeier et al., 1995). However, depolarizing pulses applied to inject neurobiotin were below spike threshold, thus preventing calcium entry during the action potential. Since the dopamine-induced reduction in dye coupling was antagonized by the PKA inhibitor Rp-cAMPS, an indirect effect via changes in intra- or extracellular $\mathrm{pH}$ can be excluded. It has been shown that activation of adenylyl cyclase and PKA results in a decrease in open probability of gap junction channels in retinal neurons (Lasater, 1987; McMahon and Brown, 1994). Thus, the most likely explanation for the reduc- tion in dye coupling induced by PKA in neocortical neurons is phosphorylation of connexins, which are endowed with several serine phosphorylation sites (see Bayer, 1993, for review).

The uncoupling effect of dopamine in the developing rat neocortex was mediated by both dopamine D1 and D2 receptors. D2 receptors are known to reduce intracellular cAMP concentrations (Onali et al., 1984; Battaglia et al., 1985; Weiss et al., 1985); however, a linkage to other second-messenger pathways has been shown (Piomelli et al., 1987; Kanterman et al., 1991, Jackson and Westlind-Danielsson, 1994). The application of receptor selective agonists demonstrated that activation of either D1 or D2 receptors is sufficient to depress dye coupling. Therefore, an intracellular signal transduction system different from the cAMP pathway might be involved in the action of dopamine on gap junction permeability. Possible candidates are protein kinase C-dependent phosphorylation, calcium ions, or arachidonic acid metabolites (Rose and Loewenstein, 1975; Rao et al., 1987; Miyachi et al., 1994).

\section{Regulation of gap junctional communication-a new role for dopaminergic afferents to the developing neocortex?}

During the early postnatal period, dopaminergic terminals are present in both superficial and deep cortical layers (Berger et al., 1991). The strongest expression of both D1 and D2 receptors occurs in the deep layers, although these receptors are also existent in the superficial layers of prefrontal areas (Schambra et al., 1994). A significant increase in D1 receptor expression has been observed between the second and third postnatal week when gap junction coupling disappears and synaptogenesis increases (Leslie et al., 1991). Thus, the dopaminergic fiber system might exert a twofold function: at embryonic and early postnatal stages, dopamine might regulate metabolic and electrical signal transfer, and, by regulating electrotonic cell parameters, it might affect the efficacy of developing chemical synapses.

Layer V/VI pyramidal cells were already uncoupled, and dopamine had no significant effect on residual tracer coupling in the deep layers during the second postnatal week, suggesting that uncoupling follows a developmental gradient reflecting the "inside-first outside-last" pattern of neurogenesis in the neocortex.

Dopamine has been suggested to act as a neurotrophic factor during development of the neocortex, since lesioning of dopaminergic afferents reduces cortical thickness (Kalsbeek et al., 1987) and impairs the development of cortical neurons (Kalsbeek et al., 1989). In the adult rat prefrontal cortex, dopamine potentiates GABAergic synaptic transmission via a presynaptic mechanism (Penit-Soria et al. 1987; Sutor and Mayr, 1991) and shifts the balance between long-term potentiation and long-term depression in favor of long-term depression (Law-Tho et al., 1995). Thus, the functions of the dopaminergic projection to the neocortex obviously change during development.

\section{References}

Battaglia G, Norman AB, Hess EJ, Creese I (1985) D2 dopamine receptor-mediated inhibition of forskolin-stimulated adenylate cyclase in rat striatum. Neurosci Lett 59:177-182.

Bayer EC (1993) Gap junctions. Int Rev Cytol 137C:1-37.

Berger B, Verney C, Alvarez C, Vigny A, Helle KB (1985) New dopaminergic terminal fields in the motor, visual (area 18b) and retrosplenial cortex in the young and adult rat. Immunocytochemical and catecholamine histochemical analysis. Neuroscience 15:983-998.

Berger B, Gaspar P, Verney C (1991) Dopaminergic innervation of the cerebral cortex: unexpected differences between rodents and primates. Trends Neurosci 14:21-27. 
Blanton MG, LoTurco JJ, Kriegstein $\Lambda \mathbf{R}$ (1989) Whole cell recordings from neurons in slices of reptilian and mammalian cerebral cortex. J Neurosci Methods 30:203-210.

Burt JM, Spray DC (1988) Inotropic agents modulate gap junctional conductance between cardiac myocytes. Am J Physiol 254:12061210 .

Cepeda J, Walsh JP, Hull CD, Howard SG, Buchwald NA, Levine MS (1989) Dye coupling in the striatum of the rat. I. Modulation by dopamine-depleting lesions. Synapse 4:229-237.

Cepeda J, Walsh JP, Peacock W, Buchwald NA, Levine MS (1993) Dye-coupling in human neocortical tissue resected from children with intractable epilepsy. Cereb Cortex 3:95-107.

Connors BW, Benardo LS, Prince DA (1983) Coupling between neurons of the developing rat neocortex. J Neurosci 3:773-782.

Connors BW, Benardo LS, Prince DA (1984) Carbon dioxide sensitivity of dye coupling among glia and neurons of the neocortex. J Neurosei 4:1324-1330.

Dearry A, Gingrich JA, Faladeau P, Fremeau RT, Bates MD, Caron MG (1990) Molecular cloning and expression of the gene for human DI dopamine receptor. Nature 278:72-76.

DeMello WC (1983) The influence of $\mathrm{pH}$ on the healing-over of mammalian cardiac muscle. J Physiol (Lond) 339:299-307.

DeMello WC (1989) Effect of isoproterenol and 3-isobutyl-1-methylxanthine on junctional conductance in heart cell pairs. Biochim Biophys Acta 1012:291-298.

DeVries SH, Schwartz EA (1992) Hemi-gap-junction channels in solitary horizontal cells of the catfish retina. J Physiol (Lond) 445:201230.

Goldman-Rakic PS, Leranth C, Willians SM, Mons N, Geffard M (1989) Dopamine synaptic complex with pyramidal neurons in primate cerebral cortex. Proc Natl Acad Sci USA 86:9015-9019.

Gutnick MJ, Connors BW, Prince DA (1982) Mechanisms of neocortical epileptogenesis in vitro. J Neurophysiol 48:1321-1335.

Hampson ECGM. Vaney DI, Weiler R (1992) Dopaminergic modulation of gap junction permeability between amacrine cells in mammalian retina. J Neurosci 12:4911-4922.

Hiramatsu T, Kume H, Kotlikoff M, Takagi K (1994) Role of calciumactivated potassium channels in the relaxation of tracheal smooth muscle by forskolin. Clin Exp Pharmacol Physiol 21:367-375.

Jackson DM, Westlind-Danielson A (1994) Dopamine receptors: molecular biology, biochemistry and behavioural aspects. Pharmacol Ther 64:291-369.

Kalsbeek A, Buijs RM, Hofman MA, Matthijsen MAH, Pool CW, Uylings HBM (1987) Effects of neonatal thermal lesioning of the mesocortical dopaminergic projection on the development of the rat prefrontal cortex. Dev Brain Res 32:123-132.

Kalsbeek A, Voorn P, Buijs RM, Pool LW, Uylings HBM (1988) Development of the dopaminergic innervation in the prefrontal cortex of the rat. J Comp Neurol 269:58-62.

Kalsbeek A, Matthissen MAH, Uylings HBM (1989) Morphometric analysis of prefrontal cortical development following neonatal lesioning of the dopaminergic mesocortical projections. Exp Brain Res 78:279-289.

Kandler K, Douglas SB, Katz LC (1994) Neuronal dye-coupling and spontaneous activity are inversely related in developing ferret visual cortex. Soc Neurosci Abstr 20:215.

Kanterman RY, Mahan LC, Briley EM, Monsma FJ, Sibley DR, Axelrod J, Felder CC (1991) Transfected D2 dopamine receptors mediate the potentiation of arachidonic acid release in Chinese hamster ovary cells. Mol Pharmacol 39:364-369.

Lasater EM (1987) Retinal horizontal cell gap junctional conductance is modulated by dopamine through a cyclic-AMP-dependent protein kinase. Proc Natl Acad Sci USA 84:7319-7323.

Lasater EM, Dowling JE (1985) Dopamine decreases conductance of the electrical junctions between cultured retinal horizontal cells. Proc Natl Acad Sci USA 82:3025-3029.

Law-Tho D, Desce JM, Crepel F (1995) Dopamine favours the emergence of long-term depression versus long-term potentiation in slices of rat prefrontal cortex. Neurosci Lett 188:125-128.

Lee WL, Hablitz JJ (1991) Initiation of epileptiform activity by excitatory amino acid receptors in the disinhibited rat neocortex. J Neurophysiol 65:87-95.

Leslie CA, Robertson MW, Cutler AJ, Bennett JP (1991) Postnatal development of DI dopamine receptors in the medial prefrontal cortex, striatum and nucleus accumbens of normal and neonatal 6-hy- droxydopamine treated rats: a quantitative autoradiographic analysis. Dev Brain Res 62:109-114.

Lidow MS (1995) D1 and D2 dopaminergic receptors in the developing cerebral cortex of macaque monkey: a film autoradiographic study. Neuroscience 65:439-452.

Lo Turco JJ, Kriegstein AR (1991) Clusters of coupled neuroblasts in embryonic neocortex. Science 252:563-566.

MacMahon DG (1994) Modulation of electrical synaptic transmission in zebrafish retinal horizontal cells. J Neurosci 14:1722-1734.

McMahon DG, Brown DR (1994) Modulation of gap-junction channel gating at zebrafish retinal electrical synapses. J Neurophysiol 72: 2257-2259.

Miyachi EI, Kato C, Nakaki T (1994) Arachidonic acid blocks gap junctions between retinal horizontal cells. Neuroreport 5:485-488.

Monsma FJ, Mahan LC, McVittie LD, Gerfen CR, Sibley DR (1990) Molecular cloning and expression of a DI dopamine receptor linked to adenylyl cyclase activation. Proc Natl Acad Sci USA 87:67236727.

Moreno AP, Fishman GI, Spray DC (1992) Phosphorylation shifts unitary conductance and modifies voltage dependent kinetics of human connexin 43 gap junction channels. Biophys $\mathrm{J}$ 62:51-53.

Nicoll RA, Malenka RC, Kauer JA (1990) Functional comparison of neurotransmitter receptor subtypes in mammalian central nervous system. Physiol Rev 70:513-565.

O'Donnell P, Grace AA (1993) Dopaminergic modulation of dye coupling between neurons in the core and shell regions of the nucleus accumbens. J Neurosci 13:3456-3471.

Onali P, Olianas M, Gessa GL (1984) Selective blockade of dopamine D1 receptors by SCH 23390 discloses striatal dopamine D2 receptors mediating the inhibition of adenylate cyclase in rats. Eur $\mathbf{J}$ Pharmacol 99:127-128.

Onali P, Olianas M, Gessa GL (1985) Characterization of dopamine receptors mediating inhibition of adenylyl cyclase activity in rat striatum. Mol Pharmacol 28:138-145.

Ono K, Fozzard HA, Hanck DA (1995) A direct effect of forskolin on sodium channel bursting. Eur J Physiol 429:561-569.

Peinado A, Yuste R, Katz LC (1993) Extensive dye coupling between rat neocortical neurons during the period of circuit formation. Neuron $10: 103-114$.

Penit-Soria J, Audinat E, Crepel F (1987) Excitation of prefrontal cortical neurons by dopamine: an in vitro electrophysiological study. Brain Res 425:263-274

Piccolino M, Neyton J, Gerschenfeld HM (1984) Decrease of gap junction permeability induced by dopamine and cyclic adenosine $3^{\prime}, 5^{\prime}$ mono-phosphate in horizontal cells of the turtle retina. J Neurosci 4:2477-2488

Piomelli D, Volterra A, Dale N, Siegelbaum SA, Kandel ER, Schwartz JH, Belardetti $\mathrm{F}$ (1987) Lipoxygenase metabolites of arachidonic acid as second messengers for synaptic inhibition of Aplysia sensory cells. Nature 328:38-45.

Rao G, Barnes CA, McNaughton BL (1987) Occlusion of hippocampal electrical junctions by intracellular calcium injection. Brain Res 408: 267-270.

Rörig B, Klausa G, Sutor B (1995) Intracellular acidification reduces dye coupling and alters electrotonic properties of developing layer II/ III pyramidal neurons in rat neocortex. Proceedings of the 23rd Göttingen Neurobiology Conference, Vol 1, p 344.

Rose B, Loewenstein WR (1975) Permeability of cell junction depends on local cytoplasmic calcium activity. Nature 254:250-252.

Saez JC, Spray DC, Nairn AC, Hertzberg EL, Greengard P, Bennett MVL (1986) CAMP increases junctional conductance and stimulates phosphorylation of the $27 \mathrm{kDa}$ principal gap junction polypeptide. Proc Natl Acad Sci USA 83:2473-2477.

Schambra UB, Duncan GE, Breese GR, Fornaretto MG, Caron MG, Fremeau RT (1994) Ontogeny of D1A and D2 receptor subtypes in rat brain using in situ hybridization and receptor binding. Neuroscience 62:65-85.

Schmidt RH, Björklund A, Lindvall O, Loren I (1982) Prefrontal cortex: dense dopaminergic input in the newborn rat. Dev Brain Res $5: 222-228$.

Schwartz J-C, Giros B, Martres M-P, Skoloff P (1992) The dopamine receptor family: molecular biology and pharmacology. Semin Neurosci 4:99-108

Surmeier DJ, Bargas J, Hemmings HC, Nairn AC, Greengard P (1995) 
Modulation of calcium currents by a Dl dopaminergic protein kinase/ phosphatase cascade in rat neostriatal neurons. Neuron 14:385-397.

Sutor B, Mayr B (1991) Dopamine-induced modulation of synaptic transmission in rat neocortical neurons in vitro. Pflugers Arch 418(Suppl 1):R10.

Teranishi T, Negishi K, Kato S (1983) Dopamine modulates S-potential amplitude and dye-coupling between external horizontal cells in carp retina. Nature 301:243-246.

Van Hasstert PJM, Driel RV, Jastorff B, Baraniak J, Stec WJ, De Wit RJW (1984) Competitive cAMP antagonists for cAMP-receptor proteins. J Biol Chem 259:10020.

Verney C, Berger G, Adrian J, Vigny A, Gay M (1982) Development of the dopaminergic innervation of the rat cerebral cortex: a light microscopic immunocytochemical study using anti-tyrosine hydroxylase antibodies. Dev Brain Res 5:41-52.

Verney C, Alvarez C, Geffard M, Berger B (1990) Ultrastructural dou- blc-labclling study of dopamine terminals and GABA-containing neurons in rat anteromedial cerebral cortex. Eur J Neurosci 2:960972.

Wang L-Y, Salter MW, MacDonald JF (1991) Regulation of kainate receptors by cAMP-dependent protein kinase and phosphatases. Science 253:1132-1135.

Weiss S, Serben M, Garcia-Sainz JA, Bockart J (1985) D2 dopamine receptor-mediated inhibition of cyclic AMP formation in striatal neurons in primary culture. Mol Pharmacol 27:595-599.

Yuste R, Peinado A, Katz LC (1992) A system of neuronal domains in developing neocortex. Science 257:665-668.

Yuste R, Nelson DA, Rubin WW, Katz LC (1995) Neuronal domains in developing neocortex: mechanisms of coactivation. Neuron 14:717.

Zhou QY, Grandy D, Thambi L, Kushner J, Van Tol HHM et al. (1990) Cloning and expression of human and rat DI dopamine receptors. Nature 347:76-80. 